\title{
Sources, concentrations, and risks of naphthalene in indoor and outdoor air
}

\begin{abstract}
Naphthalene is a ubiquitous pollutant, and very high concentrations are sometimes encountered indoors when this chemical is used as a pest repellent or deodorant. This study describes the distribution and sources of vapor-phase naphthalene concentrations in four communities in southeast Michigan, USA. Outdoors, naphthalene was measured in the communities and at a near-road site. Indoors, naphthalene levels were characterized in 288 suburban and urban homes. The median outdoor concentration was $0.15 \mu \mathrm{g} / \mathrm{m}^{3}$, and a modest contribution from rush-hour traffic was noted. The median indoor long-term concentration was $0.89 \mu \mathrm{g} / \mathrm{m}^{3}$, but concentrations were extremely skewed and $14 \%$ of homes exceeded $3 \mu \mathrm{g} / \mathrm{m}^{3}$, the chronic reference concentration for non-cancer effects, $8 \%$ exceeded $10 \mu \mathrm{g} / \mathrm{m}^{3}$, and levels reached $200 \mu \mathrm{g} /$ $\mathrm{m}^{3}$. The typical excess individual lifetime cancer risk was about $10^{-4}$ and reached $10^{-2}$ in some homes. Important sources include naphthalene's use as a pest repellent and deodorant, migration from attached garages and, to lesser extents, cigarette smoke and vehicle emissions. Excessive use as a repellent caused the highest concentrations. Naphthalene presents high risks in a subset of homes, and policies and actions to reduce exposures, for example, sales bans or restrictions, improved labeling, and consumer education, should be considered.

\section{S. Batterman ${ }^{1}$, J.-Y. Chin ${ }^{1}$, C. Jia ${ }^{2}$, C. Godwin' ${ }^{1}$, E. Parker ${ }^{3}$, T. Robins' ${ }^{1}$, P. Max', T. Lewis ${ }^{1}$}

'University of Michigan, Ann Arbor, MI, USA,

¿University of Memphis, Memphis, TN, USA,

${ }^{3}$ University of lowa, lowa City, IA, USA, ${ }^{4}$ Detroit

Department of Health and Wellness Promotion, Detroit, $\mathrm{Ml}$, USA

Key words: Exposure; Deodorizer; Indoor air; Mothballs; Naphthalene; Risk; Volatile organic compound; Repellent.

S. Batterman

University of Michigan

1420 Washington Heights

Room 6507 SPH2

Ann Arbor

MI 48109-2029, USA

Tel.: +1 7347632417

Fax: +1 7349367283

e-mail: stuartb@umich.edu

Received for review 3 November 2011. Accepted for publication 25 November 2011.

\section{Practical Implications}

Long-term average concentrations of naphthalene in most homes fell into the $0.2-1.7 \mu \mathrm{g} / \mathrm{m}^{3}$ range reported as representative in earlier studies. The highly skewed distribution of concentrations results in a subset of homes with elevated concentrations and health risks that greatly exceed US EPA and World Health Organization (WHO) guidelines. The most important indoor source is the use of naphthalene as a pest repellant or deodorant; secondary sources include presence of an attached garage, cigarette smoking, and outdoor sources. House-to-house variation was large, reflecting differences among the residences and naphthalene use practices. Stronger policies and educational efforts are needed to eliminate or modify indoor usage practices of this chemical.
\end{abstract}

\section{Introduction}

Naphthalene is both a volatile organic compound (VOC) and a polycyclic aromatic hydrocarbon (PAH) that is ubiquitous in indoor and outdoor air. Potentially important emission sources for the public include vehicle exhaust, evaporated gasoline, cigarette smoke, moth and pest repellants, and deodorizers (e.g., diaper pail and toilet). Important occupational settings for exposure include mothball manufacturing, creosote treating, and production of phthalic anhydride, phthalate plasticizers, and resins (ATSDR 2005; Preuss et al., 2003). Naphthalene is classified as a possible human carcinogen and, if approved, the draft inhalation cancer unit risk estimate (URE or slope factor) under consideration by US EPA (2004) of $1 \times 10^{-4} \mu \mathrm{g} /$ $\mathrm{m}^{3}$, which is based on respiratory epithelial adenomas and olfactory epithelial neuroblastomas in rats, would represent a threefold increase in its potency over the existing URE. US EPA also has established a chronic reference concentration (RfC) of $3 \mu \mathrm{g} / \mathrm{m}^{3}$ for noncancer effects, which is based on hyperplasia in respiratory epithelium and metaplasia in olfactory epithelium in mice. WHO (2010) has recently reviewed 
the toxicity of naphthalene and established an annual average indoor air quality guideline of $10 \mu \mathrm{g} / \mathrm{m}^{3}$. This guideline is based on respiratory tract lesions, including tumors in the upper respiratory tract demonstrated in animal studies, and hemolytic anemia in humans, especially in susceptible individuals with glucose-6phosphate dehydrogenase deficiency. We recently reviewed the literature regarding naphthalene concentrations in ambient, indoor, and personal settings and suggested typical ranges in residences and other environments, for example, among the studies believed to be representative, average concentrations ranged from 0.18 to $1.7 \mu \mathrm{g} / \mathrm{m}^{3}$ in non-smoker's homes (Jia and Batterman, 2010). We also noted inadequacies of the database, the need for larger and more representative exposure studies, and the lack of information pertinent to high-end exposures.

Naphthalene exposures differ from those of most other VOCs given its use in essentially pure form as a pest repellent and deodorant in homes and typically in or near bedrooms. This chemical is commonly available and inexpensive. Van Winkle and Scheff (2001) reported elevated concentrations in ten residences because of indoor storage of mothballs. There are anecdotal reports of a variety of off-label uses, although information regarding the likelihood or the significance of such events is not available. The bulk of naphthalene exposure results from occurs sublimation of solid-phase naphthalene, volatilization of fuels containing naphthalene, and combustion products. The adsorption and subsequent release of naphthalene from clothes represents another exposure pathway (Guerrero and Corsi, 2011).

This paper updates information on current concentrations of vapor-phase naphthalene in indoor and outdoor settings in a wide range of residences in four cities in southeast Michigan. We characterize indoor levels, variance contributions, and distributions in four diverse cities, especially the high-end distributions. Additionally, we examine temporal and spatial trends of ambient concentrations, estimate contributions from the major indoor sources such as cigarettes, attached garages and mothballs, and predict cancer risks caused by naphthalene exposure.

\section{Methods}

Sampling sites

Naphthalene concentrations were monitored in four communities in southeast Michigan, USA (Figure 1). Ann Arbor (AA) is a largely suburban and affluent community. Ypsilanti (YP) is more commercial and industrial. Dearborn (DB) and Detroit (DT) are densely populated and industrialized cities, and household income tends to be considerably lower. Several techniques were used to recruit a total of 288 households in these four communities. Random sampling via telephone dialing and snowball recruitment techniques was used to recruit 65 households in AA, 35 in YP, and 61 in DB, as part of VOC exposure study. In DT, 127 households were recruited via questionnaires distributed

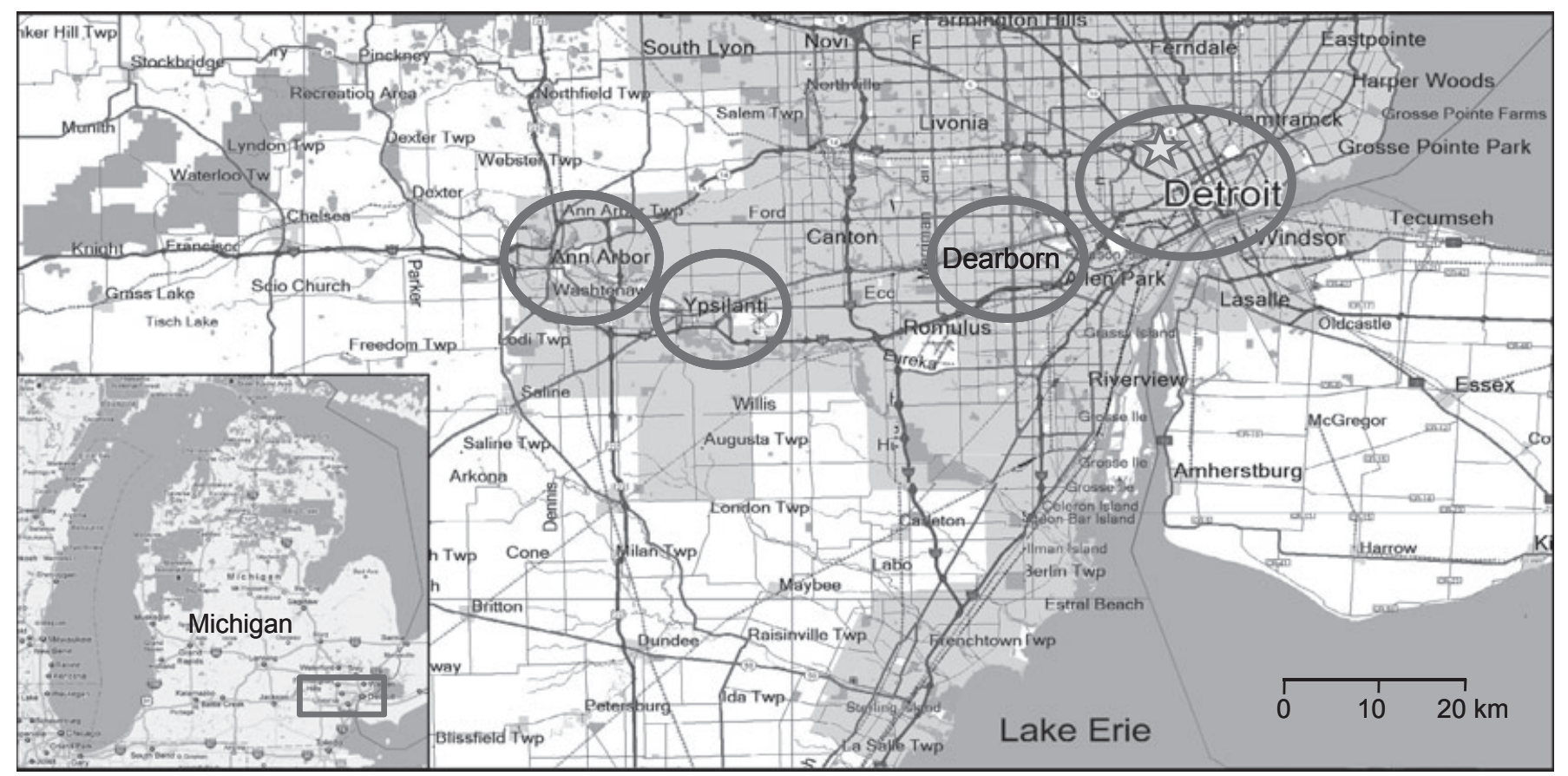

Fig. 1 Map showing study region. Ovals indicate four studied cities, and the star indicates location of the near-road monitoring site. Inset map shows study region within State of Michigan 


\section{Batterman et al.}

to caregivers at community-based organizations, schools, community fairs, and other venues, and households selected for this study were required to have at least one child 6-12 years old with symptoms or medication use consistent with persistent asthma. The DT component was conducted as part of a community-academic partnership asthma study (Parker et al. 2008). In each house, questionnaires and building walk-through audits were used to obtain information on housing, smoking, work, and family characteristics, hobbies, and other factors potentially related to exposure. House characteristics in AA, YP, and DB have been described by Jia et al. (2008a,b), and DT homes have been described by Du et al. (2011). Study protocols followed informed consent, and other procedures approved by the Institutional Review Board of the University of Michigan.

Each residence was visited in several seasons. AA and YP residences were visited in summer 2004 and winter 2005. DB residences were visited in fall 2004 and spring 2005. In the second season in these cities, 31 additional residences were recruited to replace 26 dropouts, and additional follow-up studies took place in an additional eight AA residences in summer 2005. In DT, households entered the study on a rolling basis between March 2009 and February 2010. Follow-up studies in this city were completed by October 2010, and 11 homes had one visit, 17 had two visits, 87 had three visits, and 12 had four (or more) visits. In AA, YP and DB, indoor and outdoor samples were collected simultaneously. Indoor samplers were deployed in duplicate in the living room, and outdoor samplers were deployed in duplicate at the location close to the house, for example, the backyard. Outdoor samples were not collected in a small portion $(10 \%)$ of homes because of inclement weather or lack of appropriate location, and each location was sampled in duplicate or triplicate. In DT, indoor samples were collected (single or duplicate samples) in the living room, and duplicate samples in the child's bedroom. Outdoor concentrations in DT were monitored at a central site using active sampling (described later).

A technician completed a standardized walk-through inspection to collect information on each home's characteristics and condition, for example, type of heating and cooling system, presence of an attached garage, and emission sources such as candles, incense, and room deodorizers. For brevity, we did not inquire about specific uses and application rates of naphthalene products in the inspections, but instead depended on the naphthalene measurements to indicate its use. Tracers of environmental tobacco smoke (ETS), 2,5-dimethyl furan and 3-ethenyl pyridine, were also measured (Charles et al., 2008). While low levels of ETS may not always be identified, ETS is nearly certainly present if these tracers are detected.
Naphthalene, the ETS tracers, and other VOCs were measured using passive thermal desorption tube samplers over a 3- to 7-day period (Batterman et al., 2002). In each home, samplers were deployed $\geq 0.6 \mathrm{~m}$ above the floor and below the ceiling, away from windows, doors, and obvious sources of potential contaminants, $\geq 0.5 \mathrm{~m}$ away from bookshelves and other potentially stagnant areas, and out of the reach of children. Except for the variance analyses (described later), concentrations in the two spaces were averaged and treated as a single observation, and concentrations in different seasons in each house were averaged. Thus, each observation represents the average of replicates, two rooms for the DT homes, and at least two seasons. Overall, the monitoring campaign collected 1439 valid indoor samples (245 single samples, 487 duplicates, 48 triplicates, 19 quadruplicates) and 478 residential outdoor samples (one single sample, 204 duplicates, 23 triplicates), excluding samples considered invalid owing to sampling or analysis issues.

To examine trends in ambient air, 24-h VOC samples were collected daily at the DT Department of Health and Wellness Promotion Herman Kiefer complex located in central DT, at a site $60 \mathrm{~m}$ east-southeast (ESE) of the Lodge Freeway (M-10). At this near-road location, the freeway is slightly below grade, the annual average daily traffic (AADT) was 143300 vehicles/day, and the daily commercial annual average daily traffic (CADT) was 2600 vehicles/day (Michigan Department of Transportation 2009). The area surrounding the Kiefer complex is primarily residential. Using an automated sequential sampler, an active sample flow regulated by a mass flow controller, and the same thermal desorption tubes described, calendar day 24-h samples were collected from August 15, 2009, to August 16, 2010, at $5 \mathrm{ml} / \mathrm{min}$, and from August 17, 2009, to April 19, 2011, at $2.5 \mathrm{ml} / \mathrm{min}$. Possible impacts of rush-hour traffic were investigated by collecting 3-h samples daily from 6:00 to 9:00 $\mathrm{Am}$ at the same site using a second sequential sampler at a flow rate of $10 \mathrm{ml} / \mathrm{min}$ from January 26 to March 29, 2011. These flow rates represent a compromise between obtaining sufficient sampling volume and minimizing problems associated with excess water. The active sampling at the Kiefer site represented another 548 daily/valid samples. About $10 \%$ of the Kiefer samples failed owing to rain events and instrument failures.

All samples were analyzed using an automated thermal desorption-gas chromatography-mass spectrometry (ATD-GC-MS) system (Jia et al., 2006). Given the high naphthalene concentrations sometimes encountered indoors, our standard 7-point calibration, which used concentrations between 0.2 and $200 \mu \mathrm{g} / \mathrm{m}^{3}$, was extended to $500 \mu \mathrm{g} / \mathrm{m}^{3}$ where it continued to show excellent linearity. Quality assurance measures to ensure reproducibility and data quality included the use of standard operating protocols, routine collection and 
analysis of blanks (weekly at each site), regular flow checks, quarterly calibrations, and duplicate and sometime triplicate samples. The method detection limit (MDL), established using low-concentration spiked samples, was $<0.08 \mu \mathrm{g} / \mathrm{m}^{3}$, and replicate precision was generally $\leq 20 \%$. Non-detects were set to $1 / 2 \mathrm{MDL}$.

\section{Data analysis}

Random effects models were applied to differentiate the variance of the naphthalene concentrations into five component parts (Jia et al., 2011):

$$
\operatorname{Var}\left(Y_{i j k l}\right)=\sigma_{\mathrm{C}}^{2}+\sigma_{\mathrm{R}}^{2}+\sigma_{\mathrm{H}}^{2}+\sigma_{\mathrm{S}}^{2}+\sigma_{\mathrm{E}}^{2}
$$

where $\sigma_{\mathrm{C}}^{2}$ and $\sigma_{\mathrm{R}}^{2}=$ spatial variability calculated as the variances between cities and between residences, respectively; $\sigma_{\mathrm{H}}^{2}=$ variability between bedroom and living measurements in the same home; $\sigma_{\mathrm{S}}^{2}=$ seasonal variability calculated as the variance between seasons; and $\sigma_{\mathrm{E}}^{2}=$ measurement uncertainty calculated as the variance between replicates. This analysis was performed for both indoor (AA, YP, DB, and DT) and outdoor (AA, YP, and DB) concentrations. Naphthalene concentrations were right-skewed; thus, statistical analyses used log-transformed data because the random effects models assume normality. Variance components were computed using the MIXED procedure in SAS (v9.1.3; SAS Institute, Cary, NC, USA).

For the DT outdoor data, effects of season, day-ofweek and weekday vs. weekend were evaluated using Kruskal-Wallis tests, and concentrations during the 3-h morning rush-hour period and the corresponding 24-h sample were compared using Wilcoxon signedranks test. Trends were fit using an exponential smoother ( $\alpha=0.05$ per day) and linear regression. Differences among indoor measurements also used Kruskal-Wallis tests. These analyses used SPSS 17 (IBM Corp., Somers, NY, USA). Data and results were organized in Microsoft Excel 2003.

Excess lifetime cancer risk was estimated as the product of the naphthalene concentration $\left(\mu \mathrm{g} / \mathrm{m}^{3}\right)$ and the draft US EPA (2004) cancer URE. This simple 'screening' level estimate makes several important assumptions: it does not account for exposures in environments other than the home; measurements are assumed to be representative of long-term or lifetime exposure; and the outcome represents an upper-bound (95th percentile) risk estimate.

\section{Results}

Outdoor concentrations

The mean and median naphthalene concentrations outside homes in AA, YP, and DB were 0.28 and $0.16 \mu \mathrm{g} / \mathrm{m}^{3}$, respectively $(N=145$; Table 1$)$. The var- iance proportions analysis showed that effects of season were the strongest ( $49 \%$ of the total variance), followed by city $(28 \%)$, measurement uncertainty $(17 \%)$, and house-to-house variation $(7 \%$; Table 2$)$. The relatively high city-to-city variation likely reflects differences in terms of urbanization and industrialization, while the rather negligible between-house variation indicates that concentrations are homogeneous within a neighborhood, a result driven largely by the AA results. Variance analyses computed for each city showed several differences (Table 2), for example, in AA, effects of season were the strongest $(78 \%)$ followed by measurement uncertainty, while in YP and DB, house-to-house variations were the strongest $(50-58 \%)$, followed by season $(28-31 \%)$ and measurement uncertainty (12-22\%). The house-to-house variation in YP and DB reflected multiple and unevenly distributed emission sources. Because the outdoor samplers were deployed close to houses, the measurements may reflect both the local neighborhood and very local activities, for example, use of barbeques, lawnmowers, and gardening. While the measurement reproducibility deteriorated at low concentrations, it remained within the $25 \%$ criterion for the TO- 15 method (US EPA 1999).

At the near-road monitoring site, the median naphthalene concentration was $0.15 \mu \mathrm{g} / \mathrm{m}^{3}$ and nearly identical to the neighborhood samples just discussed, and the 24-h samples reached a maximum of $1.2 \mu \mathrm{g} / \mathrm{m}^{3}$ (Table 3). Seasonal variation was significant $(P<0.05)$, and concentrations were highest in winter $2010\left(0.29 \pm 0.15 \mu \mathrm{g} / \mathrm{m}^{3}\right)$ and lowest in spring 2011 $\left(0.09 \pm 0.04 \mu \mathrm{g} / \mathrm{m}^{3}\right)$. Day-of-week and weekdayweekend differences were not significant $(P=0.63$ and $P=0.33$, respectively). Figure 2 shows the trend of daily concentrations monitored for nearly 2 years. Seasonal patterns were not consistent, for example, the smoothed trend showed the highest levels in winter, summer and fall of 2010, and a relatively small number of peaks was influential. A linear trend fit to the data shows a gradual decline in concentrations over the study period with a decrease of about $30 \%$ per year; however, the linear model may not have much explanatory or predictive value. Declining trends of toluene, ethylbenzene, $p$-m-xylene, and other VOCs were seen at this site, while benzene and carbon tetrachloride showed slightly ascending trends. We could not identify the specific cause of these trends, which might include decreases in traffic and reductions in other emission sources. Analytical issues were not implicated based on our calibrations and quality assurance measures.

Naphthalene concentrations were moderately to highly correlated with concentrations of most aromatic and alkane VOCs measured at the same site, for example, benzene $(r=0.46)$, toluene $(r=0.77)$, ethylbenzene $\quad(r=0.76), \quad p$-m-xylene $\quad(r=0.60)$, 


\section{Batterman et al.}

Table 1 Indoor and outdoor concentrations of naphthalene in the four study cities

\begin{tabular}{|c|c|c|c|c|c|c|c|c|c|c|}
\hline \multirow[b]{2}{*}{ Location and statistic } & \multicolumn{5}{|c|}{ Residence-based statistics } & \multicolumn{5}{|c|}{ Visit-based statistics } \\
\hline & $\mathrm{AA}$ & YP & $\mathrm{DB}$ & DT & All & AA & YP & $\mathrm{DB}$ & DT & All \\
\hline \multicolumn{11}{|l|}{ Outdoors } \\
\hline Sample size & 53 & 35 & 57 & n.a & 145 & 85 & 58 & 81 & n.a & 224 \\
\hline Detection frequency (\%) & 100 & 100 & 100 & n.a & 100 & 100 & 100 & 100 & n.a & 100 \\
\hline \multicolumn{11}{|l|}{ Concentration $\left(\mu \mathrm{g} / \mathrm{m}^{3}\right)$} \\
\hline Mean & 0.24 & 0.12 & 0.41 & n.a & 0.28 & 0.27 & 0.13 & 0.37 & n.a & 0.27 \\
\hline Standard deviation & 0.35 & 0.09 & 0.79 & n.a & 0.55 & 0.54 & 0.11 & 0.69 & n.a & 0.54 \\
\hline Median & 0.16 & 0.10 & 0.28 & n.a & 0.16 & 0.15 & 0.09 & 0.26 & n.a & 0.16 \\
\hline 90th percentile & 0.42 & 0.21 & 0.64 & n.a & 0.46 & 0.63 & 0.29 & 0.55 & n.a & 0.53 \\
\hline 95th percentile & 0.49 & 0.30 & 0.81 & n.a & 0.70 & 0.73 & 0.37 & 0.80 & n.a & 0.72 \\
\hline 99th percentile & 1.63 & 0.41 & 3.27 & n.a & 1.87 & 4.72 & 0.53 & 6.01 & n.a & 1.77 \\
\hline Maximum & 2.47 & 0.41 & 6.01 & n.a & 6.01 & 4.72 & 0.53 & 6.01 & n.a & 6.01 \\
\hline \multicolumn{11}{|l|}{ Indoors } \\
\hline Sample size & 65 & 35 & 61 & 127 & 288 & 98 & 58 & 87 & 345 & 588 \\
\hline Detection frequency (\%) & 100 & 100 & 100 & 100 & 100 & 100 & 100 & 100 & 100 & 100 \\
\hline \multicolumn{11}{|l|}{ Concentration $\left(\mu \mathrm{g} / \mathrm{m}^{3}\right)$} \\
\hline Mean & 3.5 & 5.6 & 2.3 & 7.8 & 5.4 & 2.8 & 6.3 & 2.0 & 9.1 & 6.7 \\
\hline Standard deviation & 12.4 & 14.8 & 5.0 & 25.8 & 19.1 & 10.2 & 17.0 & 4.3 & 41.4 & 32.6 \\
\hline Median & 0.7 & 0.8 & 0.9 & 1.0 & 0.9 & 0.7 & 0.8 & 1.0 & 0.9 & 0.8 \\
\hline 90th percentile & 3.5 & 10.9 & 2.4 & 8.7 & 6.4 & 4.0 & 18.0 & 3.3 & 8.9 & 7.1 \\
\hline 95th percentile & 7.4 & 25.0 & 6.6 & 37.6 & 28.2 & 7.5 & 69.1 & 4.7 & 51.2 & 21.8 \\
\hline 99th percentile & 59.7 & 65.6 & 25.7 & 124.7 & 90.6 & 91.7 & 84.3 & 31.6 & 194.3 & 117.2 \\
\hline Maximum & 91.7 & 79.1 & 31.6 & 200.6 & 200.6 & 91.7 & 84.3 & 31.6 & 556.2 & 556.2 \\
\hline
\end{tabular}

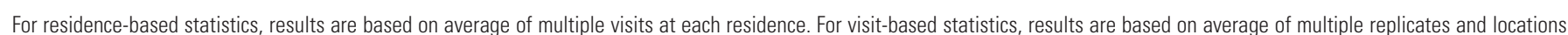

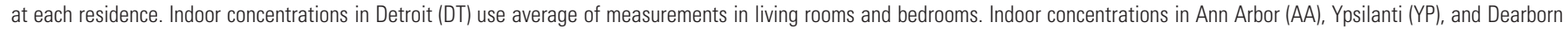

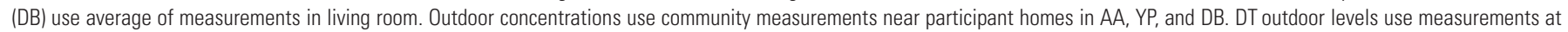
a near-roadway site.

Table 2 Variance proportions (\%) for naphthalene concentrations indoors and outdoors

\begin{tabular}{|c|c|c|c|c|c|}
\hline Location/component & All & $\mathrm{AA}$ & YP & $\mathrm{DB}$ & DT \\
\hline \multicolumn{6}{|l|}{ Outdoors } \\
\hline City & 27.5 & n.a. & n.a. & n.a. & n.a. \\
\hline Residence & 6.7 & 0.0 & 57.6 & 50.2 & n.a. \\
\hline Season & 49.0 & 77.7 & 30.7 & 28.2 & n.a. \\
\hline Measurement & 16.7 & 22.3 & 11.7 & 21.5 & n.a. \\
\hline \multicolumn{6}{|l|}{ Indoors } \\
\hline City & 0.0 & n.a. & n.a. & n.a. & n.a. \\
\hline Residence & 62.1 & 57.3 & 80.7 & 73.6 & 59.0 \\
\hline Season & 30.0 & 36.8 & 18.4 & 21.3 & 21.0 \\
\hline Measurement & 7.9 & 5.9 & 0.8 & 5.0 & 20.0 \\
\hline
\end{tabular}

AA, Ann Arbor; DB, Dearborn; DT, Detroit; YP, Ypsilanti.

$o$-xylene $(r=0.60)$, and $\mathrm{n}-\mathrm{C}_{7-15}$ alkanes $(r=0.43$ 0.64 ; all significant at $P=0.01$ ), suggesting that vehicle emissions was the main source for these VOCs. Conversely, correlation coefficients were not statistically significant between naphthalene and trichloroethylene $(r=-0.03)$, 1,4-dichlorobenzene $(r=0.07)$, cyclohexane $(r=0.04)$, and carbon tetrachloride $(r=0.00)$, indicating that these VOCs had different emission sources. Although use is banned under the Montreal Protocol, carbon tetrachloride is long-lived in the atmosphere and globally distributed, and local sources are not suspected.

During the 3-h morning rush-hour period, naphthalene concentrations were elevated by an average of $33 \%$
Table 3 Outdoor levels of naphthalene in Detroit at the near-road site

\begin{tabular}{|c|c|c|c|}
\hline \multirow[b]{2}{*}{ Sampling events } & \multirow{2}{*}{$\begin{array}{l}15 \text { August } 2009 \text { to } \\
19 \text { April } 2011\end{array}$} & \multicolumn{2}{|c|}{$\begin{array}{l}26 \text { January } 2011 \text { to } \\
29 \text { March } 2011\end{array}$} \\
\hline & & $6-9$ AM & $24 \mathrm{~h}$ \\
\hline Sample size & 548 & 52 & 61 \\
\hline Detection frequency (\%) & 99 & 100 & 100 \\
\hline \multicolumn{4}{|l|}{ Concentration $\left(\mu \mathrm{g} / \mathrm{m}^{3}\right)$} \\
\hline Average & 0.18 & 0.15 & 0.11 \\
\hline Standard deviation & 0.12 & 0.07 & 0.05 \\
\hline Median & 0.15 & 0.14 & 0.11 \\
\hline 90th percentile & 0.33 & 0.27 & 0.17 \\
\hline Maximum & 1.21 & 0.32 & 0.27 \\
\hline
\end{tabular}

compared to the daily mean (Table 2, Figure 3 ). These increments occurred on most days and were statistically significant $(P<0.001)$. Day-of-week and weekdayweekend differences were not significant for the morning rush-hour period ( $P=0.26, P=0.35$, respectively). This rush-hour differential suggests vehicle emissions, although poor ventilation and a low ceiling for atmospheric mixing can also raise levels of pollutants emitted by other local sources. Such meteorological conditions are common during the early morning period in DT. Concentrations of other VOCs were also elevated during this period, for example, benzene concentrations rose by $17 \%$ compared to the daily mean and did not show day-of-week and weekday-weekend differences, while 


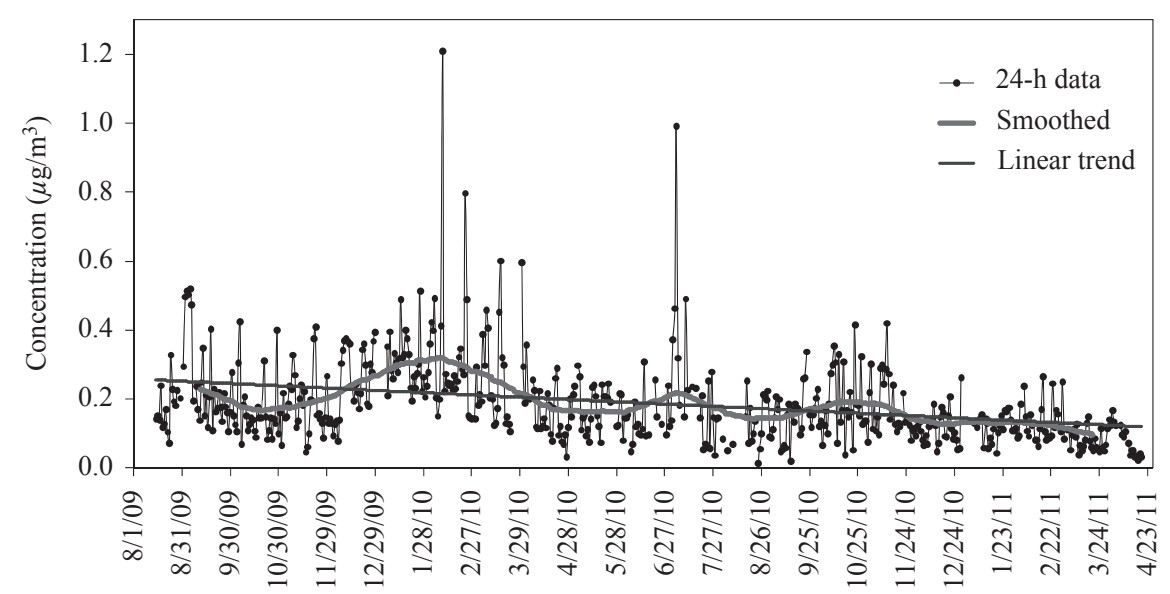

Fig. 2 Trends of naphthalene concentrations at the near-road site in Detroit

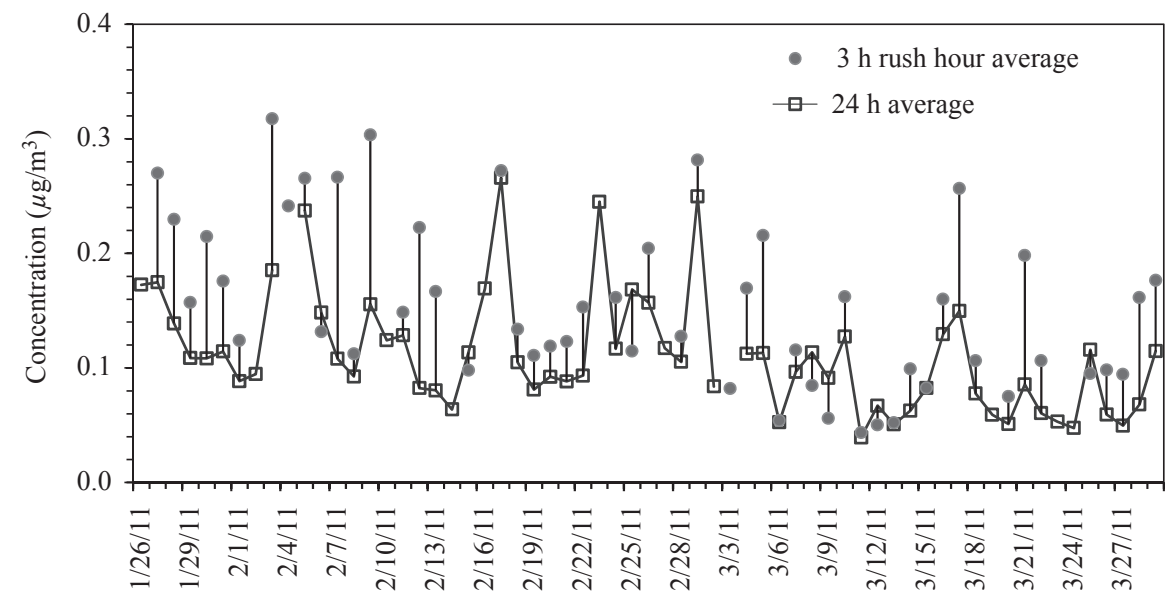

Fig. 3 Trends of naphthalene at the near-road site contrasting 3-h morning rush-hour (6-9 AM) and 24-h average concentrations

toluene concentrations rose by about $23 \%$ and showed higher concentrations on weekdays than weekends (Kruskal-Wallis test, $P<0.05$, both rush-hour and daily averages).

The central tendency of outdoor concentrations in DT is typical of levels found in 24 previous urban and suburban studies, which show medians from 0.02 to $0.31 \mu \mathrm{g} / \mathrm{m}^{3}$ and averages from 0.01 to $0.82 \mu \mathrm{g} / \mathrm{m}^{3}$ (Jia and Batterman, 2010). The highest outdoor levels, $6.0 \mu \mathrm{g} / \mathrm{m}^{3}$ in DB, $2.5 \mu \mathrm{g} / \mathrm{m}^{3}$ in AA, and $1.2 \mu \mathrm{g} / \mathrm{m}^{3}$ at the DT roadway site, are also similar to the previously reported upper-bound concentration of $5 \mu \mathrm{g} / \mathrm{m}^{3}$ (Jia and Batterman, 2010). Like other pollutants, naphthalene concentrations reflect the strength of local emission sources, the sampling location, averaging time, season, meteorology, and occasional outliers. For example, naphthalene concentrations were very low, only $0.06 \mu \mathrm{g} / \mathrm{m}^{3}$, in a southern Californian community with light traffic, and $0.58 \mu \mathrm{g} / \mathrm{m}^{3}$ in areas near high traffic roads (average of 200000 vehicles per day (Eiguren-Fernandez et al., 2004). Several tunnel studies also have shown elevated concentrations, for example,
$0.07-0.57 \mu \mathrm{g} / \mathrm{m}^{3}$ in the Lundby tunnel in Gothenburg, Sweden (Wingfors et al., 2001), and $0.4-0.8 \mu \mathrm{g} / \mathrm{m}^{3}$ in the Shing Mun tunnel in Hong Kong (Ho et al., 2009). As another indicator of vehicle emissions, we calculated ratios of naphthalene to BTEX (total of benzene, toluene, ethylbenzene, and xylenes) concentrations of 0.03 (daily average) and 0.04 (rush-hour average). Using data in Fujita et al. (2003) intended for receptor modeling, naphthalene/BTEX ratios were 0.005 along a truck-free highway in California, and 0.07 for diesel exhaust as measured at truck stops. The DT results fall between these ratios, quite reasonably suggesting that naphthalene sources included a mix of diesel and gasoline vehicles. Additional sources may include industry and, in rural areas, biomass burning (Miller et al., 2009). In the present study, the higher naphthalene levels seen in DB likely reflect both traffic and industrial sources, as compared to levels in YP and especially AA, which are largely suburban in nature (Jia et al., 2008a,b).

Like many other pollutants, naphthalene concentrations undergo diurnal variation with peaks at night, 


\section{Batterman et al.}

because of low mixing heights that build up levels from local sources, and morning peaks associated with vehicle emissions at rush-hour and diminished dispersion, as discussed earlier ( $\mathrm{Lu}$ et al., 2005; Park et al., 2002). Higher naphthalene concentrations have been reported in winter ( $\mathrm{Lu}$ et al., 2005; Park et al., 2002; Reisen and Arey, 2005; Zielinska et al., 1998), which has been attributed to decreased photochemical reaction rates (Mohamed et al., 2002), increased emissions from heating sources (Ravindra et al., 2008), and decreased dispersion because od more stable air and lower mixing heights (Cheng et al., 1997). While several studies have used a large number of measurements, long-term trends have not been investigated in any of the studies located. While the near-road measurements in DT suggest a downward trend, the variation is large and this inference is based upon measurements at a single site.

Outdoor concentrations of naphthalene were far below indoor levels in most homes (discussed in the next section) and thus will have only minor contributions to the total exposure for most persons. However, for those homes that do not contain naphthaleneemitting products, the outdoor level forms a 'floor' for indoor concentrations, thus indoor and outdoor levels will be very similar in these homes.

\section{Indoor concentrations}

Indoor concentrations in the four cities are summarized in Table 1. Residence-average naphthalene concentrations ranged from near-detection limits $\left(<0.1 \mu \mathrm{g} / \mathrm{m}^{3}\right)$ to $201 \mu \mathrm{g} / \mathrm{m}^{3}$. Naphthalene levels (medians) in DT and DB tended to exceed levels in AA and $\mathrm{YP}$, and median indoor levels varied among the four cities (Kruskal-Wallis $P=0.02$ ). However, the variance components analysis, used to differentiate among the variance contributions from home, city and season, shows that the variability of indoor naphthalene concentrations was predominantly because of hometo-home variation $(62 \%)$ and seasonal variation $(30 \%)$, while between-city effects $(0 \%)$ and measurement error (7.9) were small or negligible (Table 2). This pattern was consistent among the cities. The large between-residence variation reflected differences in naphthalene uses, source strengths, and ventilation conditions among homes. The low measurement uncertainty indicates the high precision of measurements (Jia et al., 2006). The seasonal variation reflects temporal variation in source strengths and ventilation conditions.

In DT, where samplers were deployed in both living rooms and bedrooms, the within-home variation in naphthalene concentration was modest, for example, concentrations in these rooms had an average absolute relative difference of $42 \%(N=279)$. As observed elsewhere (Batterman et al., 2007; Dodson et al., 2008), air in US homes is generally well mixed (although not completely mixed), and thus concentration gradients within a household are often modest. This was expected in the DT homes given the predominance $(87 \%)$ of forced air heating/cooling systems. Nearly the same number of high naphthalene levels (e.g., $>30 \mu \mathrm{g} /$ $\mathrm{m}^{3}$ ) were found in bedrooms and living rooms, suggesting that naphthalene's use in the child's bedroom and in other spaces occurs with about the same frequency. Because only two locations in each home were monitored, however, we could not definitively identify the locations where naphthalene was used.

The mean and median indoor naphthalene concentrations in southeast Michigan, 5.4 and $0.89 \mu \mathrm{g} / \mathrm{m}^{3}$, respectively, fell within ranges reported in the recent review paper $\left(0.8-9.5 \mu \mathrm{g} / \mathrm{m}^{3}\right.$ for means, $0.17-4.1 \mu \mathrm{g} / \mathrm{m}^{3}$ for medians, based on 21 residential studies (Jia and Batterman, 2010). Two recent papers also reported fairly similar concentrations: the mean level measured in 28 homes in DT in 2006 was $0.50 \pm 0.53 \mu \mathrm{g} / \mathrm{m}^{3}$ (Johnson et al. 2010), and the mean estimated among nine North American and European studies was $1.2 \mu \mathrm{g} / \mathrm{m}^{3}$ (Logue et al., 2011). Previously, we calculated median indoor/outdoor (I/O) ratios of 2.4-12 for naphthalene, which depended on the city (AA, YP, or DB was considered) and season (Jia et al., 2008a,b).

Distributions of indoor naphthalene concentrations were highly skewed as shown in Figure 4, and there was a large difference between means and medians, and the skewness coefficient (4.2-7.5, depending on the city). The single highest (7-day) measurement was $556 \mu \mathrm{g} / \mathrm{m}^{3}$ at a DT house. When averaged across rooms and seasons, this house also had the highest concentration $\left(201 \mu \mathrm{g} / \mathrm{m}^{3}\right)$, which exceeds the highest previously reported for residences, $144 \mu \mathrm{g} / \mathrm{m}^{3}$ (Jia and Batterman, 2010). Table 4 shows that $14 \%$ of homes exceeded the chronic RfC concentration $\left(3 \mu \mathrm{g} / \mathrm{m}^{3}\right), 8 \%$ exceeded the WHO guideline of $10 \mu \mathrm{g} / \mathrm{m}^{3}$, and $5 \%$ exceeded $30 \mu \mathrm{g} / \mathrm{m}^{3}$, ten times the chronic RfC. Again,



Fig. 4 Distributions of indoor naphthalene levels in the four study cities. Sample size $=288$ 
Table 4 Number and percentage (in parentheses) of residences with naphthalene concentrations above 3,10 , and $30 \mu \mathrm{g} / \mathrm{m}^{3}$

\begin{tabular}{|c|c|c|c|c|c|}
\hline & Ann Arbor & Ypsilanti & Dearborn & Detroit & All \\
\hline & $N(\%)$ & $N(\%)$ & $N(\%)$ & $N(\%)$ & $N(\%)$ \\
\hline Sample size & 65 & 35 & 61 & 127 & 288 \\
\hline$>3 \mu \mathrm{g} / \mathrm{m}^{3}$ & $7(11)$ & $6(17)$ & $7(11)$ & 21 (17) & 41 (14) \\
\hline$>10 \mu \mathrm{g} / \mathrm{m}^{3}$ & $3(5)$ & $3(9)$ & $4(7)$ & $13(10)$ & $23(8)$ \\
\hline$>30 \mu \mathrm{g} / \mathrm{m}^{3}$ & $2(3)$ & $1(3)$ & $2(3)$ & $10(8)$ & $15(5)$ \\
\hline
\end{tabular}

Uses multi-season whole-house average; $3 \mu \mathrm{g} / \mathrm{m}^{3}$ is the US EPA reference concentration; $30 \mu \mathrm{g} / \mathrm{m}^{3}$ is the WHO indoor air quality guideline.

some differences among the cities are shown, for example, the DT homes had the highest concentrations, and differences were largest at the highest concentrations. Houses that showed high naphthalene concentrations in one season tended to show high levels in other seasons, for example, half of the homes with levels above $30 \mu \mathrm{g} / \mathrm{m}^{3}$ in one season also showed levels above this value in a second season.

\section{Indoor sources of naphthalene}

Residences contain several sources of naphthalene. As noted, use of naphthalene as a repellent and/or deodorizer is a key source. The most common use of these repellents is against moths, but naphthalenecontaining products also are marketed to repel mosquitoes and other insects, as well as rabbits, dogs, pets, and strays (NIH 2007). The very highest indoor levels, for example, greater than perhaps $10-100 \mu \mathrm{g} / \mathrm{m}^{3}$, may suggest off-label uses of naphthalene. Griego et al. (2008) notes that Recochem, Canada, is the sole US registrant for pesticide applications of naphthalene and that off-label uses of mothballs as area fumigants (e.g., placing many mothballs on open trays in attics or other portions of homes) can elevate indoor levels by $10-300 \mu \mathrm{g} / \mathrm{m}^{3}$. Such uses have been poorly documented. Other naphthalene sources, discussed later, include the presence of an attached garage, cigarette smoking/ ETS, wood combustion, incense burning, and outdoor air. The study cities differed with respect to the fraction of homes containing smokers and attached garages (Table 5). The significance of the indoor sources is shown by the large variation between homes, the significant between-city effects in outdoor air but not in

Table 5 Number and percentage (in parentheses) of household with attached garage and detected environmental tobacco smoke (ETS) markers in the four study cities

\begin{tabular}{|c|c|c|c|c|c|}
\hline & Ann Arbor & Ypsilanti & Dearborn & Detroit & All \\
\hline & $N(\%)$ & $N(\%)$ & $N(\%)$ & $N(\%)$ & $N(\%)$ \\
\hline Sample size & 65 & 35 & 61 & 127 & 288 \\
\hline Attached garage & $25(38)$ & $20(57)$ & $2(3)$ & $9(7)$ & $56(19)$ \\
\hline ETS detected & $1(2)$ & $57(163)$ & $20(33)$ & $35(28)$ & $113(39)$ \\
\hline
\end{tabular}

indoor air and, most directly, the elevated indoor levels.

Repellent and deodorizer use. In most cases, we did not directly see naphthalene used as a repellent or deodorizer in the study houses. However, inspections of the house with the highest concentration (noted above) revealed strong odors, and the naphthalene source was identified as approximately six open boxes of mothballs placed on shelves in the basement next to an improvised clothes rack, which was suspended from the ceiling joists. Our DT-based community interviewers noted that naphthalene is commonly used as both a repellent and a deodorant, for example, they cited its use to mask odors after a house was treated for a flea infestation using fumigation and an insecticide 'bomb'. We do not have quantitative information regarding the frequency or application rate of naphthalene in the study communities, other than by inference from study measurements.

Emission factors for naphthalene moth repellents have been measured in chamber tests, and emission rates range from 0.16 to $0.19 \mathrm{mg} / \mathrm{g}$-h (Jo et al., 2008). Estimates of application rates vary widely, for example, US EPA (2008) estimates application rates from 0.25 to $0.37 \mathrm{lbs}(114-127 \mathrm{~g})$ for moth repellants in a closet or similarly sized area $\left(12 \mathrm{ft}^{3}=0.34 \mathrm{~m}^{3}\right)$, and $1 \mathrm{lb}(454 \mathrm{~g})$ per $12 \mathrm{ft}^{3}$ when used as an animal repellant (US EPA 2008). Simple calculations are used to estimate concentrations following (Price and Jayjock, 2008), for example, emission rate of $0.175 \mathrm{mg} / \mathrm{g}-\mathrm{h}$, mothball or cake weight of $32 \mathrm{~g}$ (Jo et al., 2008), and a fully mixed 'box' model. Two sets of house parameters are used: a 'worst-case' using a moderately small and 'tight' house (volume $=250 \mathrm{~m}^{3}$, air exchange rate $=0.3 / \mathrm{h}$ ), and a 'typical' house (volume = $369 \mathrm{~m}^{3}$, air exchange rate $=0.63 / \mathrm{h}$ ). Deposition and sink/source effects are ignored. For these conditions, the typical and worst-case indoor naphthalene concentrations are 24 and $75 \mu \mathrm{g} / \mathrm{m}^{3}$, respectively. For $1 \mathrm{lb}$ (454 g) of naphthalene used as an animal repellant, typical and worst-case levels are 342 and $1060 \mu \mathrm{g} / \mathrm{m}^{3}$, respectively. Actual concentrations are expected to be lower because most homeowners would probably place a few mothballs in closed closets, plastic clothes bags, clothes chests, and drawers about once per year, and such environments may have limited exchange to the rest of the home. In addition, emission rates can be affected by mass-transfer limitations (including those because of the naphthalene container itself) and also would gradually decline over time as the mass of the naphthalene solid decreases, for example, a 1-cmdiameter mothball in free air lasts about 9 months. Finally, adsorption (source-sink) of vapor-phase naphthalene will temper airborne concentrations. However, higher concentrations may result if mixing is poor, if emission rates are higher, or if additional sources are 


\section{Batterman et al.}

present. In any situation, however, indoor use of naphthalene as a repellant or deodorizer will significantly elevate indoor levels.

Exhaust and evaporative emissions in garages. Garageto-house migration of naphthalene can contribute to concentrations in the occupied portion of a residence. The median long-term concentration in study houses with an attached garage was $1.1 \mu \mathrm{g} / \mathrm{m}^{3}(N=95)$, which was marginally higher than the $0.8 \mu \mathrm{g} / \mathrm{m}^{3}$ $(N=489)$ in houses without attached garages $(P=0.15)$. Such tests do not account for factors that can mask effects of an attached garage. For example, among the DB and DT residences, few had attached garages and most were older and smaller than the AA and YP residences. Cultural and economic factors also may have led to greater use of repellents and deodorizers in DB and DT. Examining only the rather similar AA and YP homes, median naphthalene levels were statistically higher in homes with an attached garage $\left(0.9 \mu \mathrm{g} / \mathrm{m}^{3}, N=69\right)$ than those without $\left(0.7 \mu \mathrm{g} / \mathrm{m}^{3}\right.$, $N=86 ; P=0.01)$, but the effect was small. Averages (as compared to medians) showed larger differences with and without garages (5.6 vs. $2.2 \mu \mathrm{g} / \mathrm{m}^{3}$ ), but the skewed nature of the data dictates the use of medians for such comparisons.

Garages can contain high concentrations of VOCs associated with automobile exhaust, gasoline, and oil, including naphthalene (Batterman et al., 2006, 2007). We previously estimated naphthalene contributions from attached garages. In 15 suburban garages, the naphthalene concentration averaged $8.9 \pm 8.7 \mu \mathrm{g} / \mathrm{m}^{3}$ and reached $34 \mu \mathrm{g} / \mathrm{m}^{3}$ (Batterman et al., 2006), garageto-house airflows averaged $6.5 \pm 5.3 \%$ of the house air exchange, and garage sources were responsible for $35 \%$ of the indoor naphthalene levels (Batterman et al., 2007). Using average values and assuming full mixing and no losses, an indoor concentration of $0.58 \mu \mathrm{g} / \mathrm{m}^{3}$ is predicted; using the maximum reported naphthalene concentration and twice the garage-tohouse flow, the indoor concentration is $4.4 \mu \mathrm{g} / \mathrm{m}^{3}$. These predictions indicate that attached garages can make sizable contribution to indoor naphthalene levels and that attached garages may be the dominant source in houses without repellant/deodorizer use.

Tobacco smoke. Cigarette smoke is a minor naphthalene source. In study homes where smoking occurred based on the detection of the ETS tracers, the median naphthalene concentration was $1.0 \mu \mathrm{g} / \mathrm{m}^{3}(N=111)$, as compared to $0.8 \mu \mathrm{g} / \mathrm{m}^{3}(N=470)$ in homes where the tracers were not detected. This increase was small, but statistically significant $(P=0.01$, Kruskal-Wallis test). Effects because of smoking may have been obscured by several factors, for example, different frequencies of naphthalene use and different smoking rates among the communities. For example, we detected smoking in $31 \%$ of visits to DB and DT residences, but in only $7 \%$ of AA and YP visits (Table 5).

Several other studies also show that naphthalene concentrations are slightly elevated (by $0.1-0.2 \mu \mathrm{g} / \mathrm{m}^{3}$ ) in residences with cigarette smokers (Charles et al., 2008; Nazaroff and Singer, 2003). Estimates of naphthalene emissions from cigarettes range from 17 to $54 \mu \mathrm{g}$ per cigarette (Charles et al., 2008; Singer et al., 2002). To predict a 'worst-case' contribution from indoor smoking, we assumed emissions from two 'pack-a-day' smokers (40 cigarettes per day giving $90 \mu \mathrm{g} / \mathrm{h})$ and the small and 'tight' house discussed earlier. The predicted concentration from this scenario is $1.2 \mu \mathrm{g} / \mathrm{m}^{3}$. For the more 'typical' house discussed earlier, the concentration is $0.39 \mu \mathrm{g} / \mathrm{m}^{3}$. Higher concentrations may result if mixing is poor, if more cigarettes are smoked, or if there are other sources. However, these scenarios represent upper-bound cases. Overall, smoking is unlikely to elevate average naphthalene levels in residences by more than $1 \mu \mathrm{g} / \mathrm{m}^{3}$.

Other sources. Other indoor sources of naphthalene reported include domestic wood burning (Gustafson et al., 2008), incense burning ( $\mathrm{Li}$ and Ro, 2000), toilet and diaper pail deodorizers, and air fresheners (though other chemicals have largely replaced naphthalene's use in the latter application) (ATSDR, 2005). The simple and unvented cook stoves in developing countries, which use coal, wood and crop residues, can significantly elevate naphthalene concentrations (Viau et al., 2000). Older and unverified data in US EPA's Scorecard Source Ranking Database list a variety of naphthalene-containing consumer products, for example, caulks, sealants, automotive chemicals, synthetic resin and rubber adhesives, and wall coverings (US EPA, 2011). A flea control measure recommended by WHO (1997) was the treatment of floors with a solution of naphthalene in benzene, although this method is unlikely to be used in the United States owing to odors and hazards associated with these chemicals. Naphthalene is also listed as an ingredient in paints, stains, coatings, shrub killers, and fuel additives (NIH, 2007). Industrial uses are widespread, and occupational exposures may occur in the production of insecticides, tanning agents, and other organic chemicals (ATSDR 2005).

\section{Health risks}

Using the draft estimate of the cancer URE, and assuming that an individual's long-term exposure is equal to the median concentration $\left(0.89 \mu \mathrm{g} / \mathrm{m}^{3}\right)$ in the four cities, the lifetime excess cancer risk is $9 \times 10^{-5}$. The 90th percentile concentration $\left(6.57 \mu \mathrm{g} / \mathrm{m}^{3}\right)$ gives a risk estimate of $7 \times 10^{-4}$. Homes with measurements in the $100 \mu \mathrm{g} / \mathrm{m}^{3}$ range represent cancer risks in the $10^{-2}$ 
range, which places naphthalene among the top environmental risks. These values far exceed risks from other VOCs, for example, benzene (Jia et al., 2008a), and they appear to eclipse risks attributable to other indoor air pollutants that have been identified to pose chronic health risks with the exception of particulate matter and perhaps radon. The risk estimates for naphthalene are biased upwards in that they do not account for the amount of time that individuals spend in homes, the temporal variation of concentrations, other exposure sources, compartments and pathways, and they are based on a draft URE. As noted earlier (Table 4 ), $8 \%$ and $14 \%$ of homes exceeded US EPA and WHO guideline concentrations, respectively.

\section{Discussion}

On the basis of study measurements, house inspections, and the calculations in the previous section, homes with higher concentrations of naphthalene use this product as a pest repellent and possibly as a deodorizer. We did not query individuals on their use of deodorizers and repellents, and the walk-through inspection could only confirm the use of these products in a few obvious cases. When used as a moth repellent, solid naphthalene in the form of mothballs or flakes is typically placed in closed drawers, closets, and plastic bags where clothes, blankets, and other goods are stored. However, this product is sometimes more broadly applied as general insect and animal repellent by placing it on trays or other surfaces in rooms, attics, and outdoors in gardens. Such 'off-spec' uses can greatly elevate indoor concentrations. While it is uncertain whether practices of naphthalene usage differed among the four cities, it is clear that practices differed among households. In most cases, a high concentration measured in a home in one season was seen in subsequent seasons, suggesting that naphthalene was used on a more or less continuous basis.

\section{Risks and risk management}

While long-term concentrations of naphthalene were below the current chronic non-cancer RfC of $3 \mu \mathrm{g} / \mathrm{m}^{3}$ in most study homes (89\% of AA and DB homes, $83 \%$ in YP and DT homes), the median concentration of $0.89 \mu \mathrm{g} / \mathrm{m}^{3}$ confers an individual excess lifetime cancer risk near $10^{-4}$. Contemporary notions of acceptable risk fall in the $10^{-6}$ to $10^{-4}$ range. Importantly, the very skewed distribution of naphthalene concentrations produces upper-bound individual cancer risks for a subset of residences that exceeds $10^{-3}$ and even $10^{-2}$. Moreover, potentially millions of individuals are exposed to high levels. Such risks are exceptionally high, and they reflect homes in which this product is inappropriately used. The cancer risk estimates are based on a draft and controversial assessment of naphthalene's carcinogenic potential, which depends heavily on a study in male rats. However, naphthalene exposure remains of concern using the old URE, and the frequency and extent of exceedances over the noncancer chronic RfC and WHO guideline also remain problematic.

The current strategy for managing exposures and risks associated with naphthalene and other chemicals in consumer and industrial products is through rightto-know requirements. Naphthalene was listed as a carcinogen in 2002 under California's Proposition 65, the Safe Drinking Water and Toxic Enforcement Act of 1986, and as a hazardous chemical under the European Union's Regulation on Registration, Evaluation, Authorisation and Restriction of Chemicals $(\mathrm{REACH})$ with a registration deadline of 2010. Encouraged by the California rule, most of the California and much of the US market for pest repellents has shifted away from naphthalene to paradichlorobenzene. This substitute product has its own risks, and it is also listed under both California and European regulations. Despite these changes, naphthalene continues to find extensive use as a pest repellent, which undoubtedly accounts for the high concentrations found in Michigan homes and elsewhere. Unlike most of the literature, the present study emphasized high-end concentrations, which not infrequently reached high levels that are commensurate with risks that exceed health-based guidelines and other benchmarks. These results demonstrate that further actions to manage naphthalene exposures and risks are warranted. Appropriate actions could include sales bans or restrictions, improved labeling, consumer education, and promotion of non-toxic alternatives. WHO (2010) supports the former policy, stating that the 'most efficient way to prevent high exposures' is to ban the use of naphthalene-containing mothballs. The present study did not undertake a full risk-benefit analysis, which might consider the magnitude of other indoor risks, address cumulative exposures, examine in detail policy and management options, and justify the rationale needed to implement these actions in residential environments. Still, the concentrations and predicted risks for a subset of homes are strikingly high, and thus naphthalene exposure represents a widespread public health concern. In our communitybased study, we intend to provide individualized feedback to the participants in the form of a 'fact sheet' and other communications regarding these findings.

\section{Study limitations}

There are several limitations to this study. With respect to the experimental measurements in Michigan, while each home was measured at least twice, we did not characterize temporal (e.g., seasonal) variability. In 


\section{Batterman et al.}

AA, YP, and DB homes, indoor samples included only the living room. We did not account for other indoor locations (vehicles, bathrooms, workplaces, etc.) where people might be exposed to naphthalene. We were unable to document the specific uses and application rates of naphthalene in each home. It would be helpful to query occupants regarding their usage practices given its significance and the lack of information on this topic. Households in southeast Michigan may not be representative of Michigan or US residences. Unfortunately, naphthalene was not measured in NHANES, RIOPA, or other large exposure studies, nor has it been measured in studies using biomarkers or personal samples that can better account for multiple exposure compartments. A draft estimate for naphthalene's carcinogenic potential (URE) was used, although the earlier URE would not dramatically change conclusions. While several factors associated with high naphthalene concentrations are identified, and preliminary apportionments of indoor sources are made, the assessment is semiquantitative owing to large differences in the building characteristics and unmeasured covariates, for example, naphthalene application rates. Lastly, we did not measure particulate-phase naphthalene, although nearly all naphthalene is expected to be in the vapor phase.

\section{Conclusions}

Long-term average concentrations of naphthalene measured in most of the 288 Michigan homes fell into the $0.2-1.7 \mu \mathrm{g} / \mathrm{m}^{3}$ range reported as representative in earlier studies, but the distribution of concentrations was highly skewed, which led to greatly elevated health risk predictions in a subset of homes. Across the study homes, for example, $14 \%$ exceeded the $3 \mu \mathrm{g} / \mathrm{m}^{3}$ reference concentration for non-cancer effects, the excess individual lifetime cancer risk for the 'typical' (median) home was in the range of $10^{-4}$, and the cancer risk estimate exceeded $10^{-2}$ for the most exposed persons. Important indoor sources included the use of naphthalene as a pest repellant or possibly as a deodorant, the presence of an attached garage that allowed naphthalene combustion products and fuel vapors to enter the house and, to a smaller extent, cigarette smoking and outdoor sources. House-to-house varia- tion was large, reflecting differences among the residences and naphthalene use practices. Outdoor levels were much lower, even at a near-highway location where the influence of traffic was noted. These results, in particular the number of homes that had excessive concentrations of naphthalene, demonstrate the need to consider policies and educational efforts to eliminate or modify indoor usage practices of this chemical.

\section{Acknowledgements}

We appreciate the cooperation of study participants in this study and our community-based participatory research partners in Community Action Against Asthma coalition and its Steering Committee members: Arab Community Center for Economic and Social Services (ACCESS); Community Health and Social Services Center (CHASS); DT Hispanic Development Corporation (DHDC); Detroiters Working for Environmental Justice (DWEJ); Friends of Parkside (FOP); Latino Family Services (LFS); Warren/Conner Development Coalition; and the City of DT Department of Health and Wellness Promotion. We also acknowledge contributions from our field and support staff, including Andrew Ekstrom, Sonya Grant, Ashley O'Toole, Laprisha Berry-Vaughn, Leonard Brakefield, Dennis Fair, and Asyah Ali; our laboratory staff including Feng-Chiao Su, Liuliu Du, Lei Huang, Simone Charles, Gina Reinhold, Sergei Chernyak, Kevin Ferrell, Yundae Yu, Scott Roberts, Qiongyan Zhong, Huda Elasaad, and Savintha Sangameswaran; our statistical team including Bhramar Muhkerjee, Graciela Mentz, and Ricardo de Majo. The original literature review was sponsored by the Water, Air \& Climate Change Bureau of Health Canada. The Ann Arbor-, Ypsilanti-, and Dearborn-based portions of the field study were supported by American Chemistry Council (grant 2401), 'Understanding Exposure to Volatile Organic Air Toxics', and the Michigan Education and Research Center NIOSH grant T42 CC5410428 'Pilot Program Research Training Program'. The Detroit-based portion of this study was conducted as part of NIEHS grant R01-ESO14566-01A1 'A Community Based Participatory Research Intervention for Childhood Asthma Using Air Filters and Air Conditioners'.

\section{References}

ATSDR (2005) Toxicological Profile for Naphthalene, 1-Methylnaphthalene, and 2-Methylnaphthalene, Atlanta, GA, US Department of Health and Human Services, Agency for Toxic Substances and Disease Registry, 1-291

Batterman, S., Metts, T., Kalliokoski, P. and Barnett, E. (2002) Low-flow active and passive sampling of VOCs using thermal desorption tubes: theory and application at an offset printing facility, J. Environ. Monitor., 4, 361370.

Batterman, S., Hatzvasilis, G. and Jia, C.R. (2006) Concentrations and emissions of gasoline and other vapors from residential vehicle garages, Atmos. Environ., 40, 1828-1844

Batterman, S., Jia, C.R. and Hatzivasilis, G. (2007) Migration of volatile organic compounds from attached garages to residences: a major exposure source, Environ. Res., 104, 224 240 . 
Charles, S.M., Jia, C., Batterman, S.A. and Godwin, C. (2008) VOC and particulate emissions from commercial cigarettes: analysis of 2,5-DMF as an ETS tracer, Environ. Sci. Technol., 42, 1324-1331.

Cheng, L., Fu, L., Angle, R.P. and Sandhu, H.S. (1997) Seasonal variations of volatile organic compounds in Edmonton, Alberta,, Atmos. Environ., 31, 239-246.

Dodson, R.E., Levy, J.I., Spengler, J.D., Shine, J.P. and Bennett, D.H. (2008) Influence of basements, garages, and common hallways on indoor residential volatile organic compound concentrations, Atmos. Environ., 42, 1569-1581.

Du, L., Batterman, S., Parker, E., Godwin, C., Chin, J.-Y., O’Toole, A., Robins, T., Brakefield-Caldwell, W. and Lewis, T. (2011) Particle concentrations and effectiveness of free-standing air filters in bedrooms of children with asthma in detroit, Michigan. Build. Environ., 46, 2303-2313.

Eiguren-Fernandez, A., Miguel, A.H., Froines, J.R., Thurairatnam, S. and Avol, E.L. (2004) Seasonal and spatial variation of polycyclic aromatic hydrocarbons in vapor-phase and PM 2.5 in Southern California urban and rural communities, Aerosol Sci. Technol., 38, 447-455.

Fujita, E.M.C., David, E. and Zielinska, B. (2003) Diurnal and weekday variations in the source contributions of ozone precursors in California's South Coast Air Basin, J. Air Waste Manag. Assoc., 53, 844-863.

Griego, F.Y., Bogen, K.T., Price, P.S. and Weed, D.L. (2008) Exposure, epidemiology and human cancer incidence of naphthalene, Regul. Toxicol. Pharmacol., 51, S22-S26.

Guerrero, P.A. and Corsi, R.L. (2011) pDichlorobenzene $(p-D C B)$ and Naphthalene Adsorption to Clothing. Indoor Air, Conference, June 5-10, Austin, TX, USA

Gustafson, P., Ostman, C. and Sallsten, G. (2008) Indoor levels of polycyclic aromatic hydrocarbons in homes with or without wood burning for heating, Environ. Sci. Technol., 42, 5074-5080.

Ho, K.F., Ho, S.S.H., Lee, S.C., Cheng, Y., Chow, J.C., Watson, J.G., Louie, P.K.K. and Tian, L. (2009) Emissions of gas- and particle-phase polycyclic aromatic hydrocarbons (PAHs) in the Shing Mun Tunnel, Hong Kong, Atmos. Environ., 43, 6343-6351.

Jia, C. and Batterman, S. (2010) A critical review of naphthalene sources and exposures relevant to indoor and outdoor air, Int J Environ Res Public Health, 7, 29032939.

Jia, C., Batterman, S. and Chernyak, S. (2006) Development and comparison of methods using MS scan and selective ion monitoring modes for a wide range of airborne VOCs, J. Environ. Monitor., 8 , 1029-1042.
Jia, C., Batterman, S. and Godwin, C. (2008a) VOCs in industrial, urban and suburban neighborhoods. Part 1: indoor and outdoor concentrations, variation, and risk drivers, Atmos. Environ., 42, 2083-2100.

Jia, C., Batterman, S. and Godwin, C. (2008b) VOCs in industrial, urban and suburban neighborhoods, Part 2: factors affecting indoor and outdoor concentrations, Atmos. Environ., 42, 21012116.

Jia, C., Batterman, S. and Relyea, G.E. (2011) Variability of indoor and outdoor VOC measurements: an analysis using variance components, Environ. Pollut., PMID:21995872 [Epub ahead of print].

Jo, W.K., Lee, J.H., Lim, H.J. and Jeong, W.S. (2008) Naphthalene emissions from moth repellents or toilet deodorant blocks determined using head-space and smallchamber tests, J. Environ. Sci. (China), 20, 1012-1017.

Johnson, M.M., Williams, R., Fan, Z., Lin, L., Hudgens, E., Gallagher, J., Vette, A., Neas, L. and Özkaynak, H. (2010) Participant-based monitoring of indoor and outdoor nitrogen dioxide, volatile organic compound, and polycyclic aromatic hydrocarbons among MICA-Air households, Atmos. Environ., 44, 49274936.

Li, C.S. and Ro, Y.S. (2000) Indoor characteristics of polycyclic aromatic hydrocarbons in the urban atmosphere of Taipei, Atmos. Environ., 34, 611-620.

Logue, J.M., McKone, T.E., Sherman, M.H. and Singer, B.C. (2011) Hazard assessment of chemical air contaminants measured in residences, Indoor air, 21, 92-109.

Lu, R., Wu, J., Turco, R.P., Winer, A.M., Atkinson, R., Arey, J., Paulson, S.E., Lurmann, F.W., Miguel, A.H. and Eiguren-Fernandez, A. (2005) Naphthalene distributions and human exposure in a Southern California, Atmos. Environ., 39, 489-507.

Michigan Department of Transportation (2009) Average Daily Traffic (ADT) map. Available from: http://www.michigan.gov/mdot/0,1607,7-151-9622_11033_ 11149 —,00.html, last accessed on May 13, 2010.

Miller, L., Xu, X.H. and Luginaah, I. (2009) Spatial variability of volatile organic compound concentrations in sarnia, Ontario, Canada, J. Toxicol. Environ. Health. A, 72, 610-624.

Mohamed, M.F., Kang, D.W. and Aneja, V.P. (2002) Volatile organic compounds in some urban locations in United States, Chemosphere, 47, 863-882.

Nazaroff, W.W. and Singer, B.C. (2003) Inhalation of hazardous air pollutants from environmental tobacco smoke in US residences, J. Expo. Anal. Environ. Epidemiol., 14, S71-S77.
NIH. (2007) Household Products Database, National Library of Medicine specialized information services, National Institutes of Health, [updated 2007 April]. http:// householdproducts.nlm.nih.gov/cgi-bin/ household $/$ brands?tbl $=$ chem\&id $=777$ \&query $=$ naphthalene $\&$ searchas $=$ TblChemicals.

Park, S.S., Kim, Y.J. and Kang, C.H. (2002) Atmospheric polycyclic aromatic hydrocarbons in Seoul, Korea, Atmos. Environ., 36, 2917-2924.

Parker, E.A., Israel, B.A., Robins, T.G., Mentz, G., Lin, X., Brakefield-Caldwell, W., Ramirez, E., Edgren, K.K., Salinas, M. and Lewis, T.C. (2008) Evaluation of Community Action Against Asthma: a community health worker intervention to improve children's asthma-related health by reducing household environmental triggers for asthma, Health Educ. Behav., 35, 376-395.

Preuss, R., Angerer, J. and Drexler, H. (2003) Naphthalene - an environmental and occupational toxicant, Int Arch Occup Environ Health, 76, 556-576.

Price, P.S. and Jayjock, M.A. (2008) Available data on naphthalene exposures: strengths and limitations, Regul. Toxicol. Pharmacol., 51, S15-S21.

Ravindra, K., Sokhi, R. and Van Grieken, R. (2008) Atmospheric polycyclic aromatic hydrocarbons: source attribution, emission factors and regulation, Atmos. Environ., 42, 2895-2921.

Reisen, F. and Arey, J. (2005) Atmospheric reactions influence seasonal $\mathrm{PAH}$ and nitro-PAH concentrations in the Los Angeles basin, Environ. Sci. Technol., 39, 64-73.

Singer, B.C., Hodgson, A.T., Guevarra, K.S., Hawley, E.L. and Nazaroff, W.W. (2002) Gas-phase organics in environmental tobacco smoke. 1. Effects of smoking rate, ventilation, and furnishing level on emission factors, Environ. Sci. Technol., 36, 846-853.

US EPA (1999) Compendium Method TO-15, Determination of Volatile Organic Compounds (VOCs) in Air Collected in Specially-Prepared Canisters and Analyzed by Gas Chromatograpy/Mass Spectrometry $(G C / M S)$, Cincinnati, $\mathrm{OH}$, US Environmental Protection Agency, 1.

US EPA (2004) Toxicological Review of Naphthalene [External Review Draft], Washington, DC, US Environmental Protection Agency, 1-74.

US EPA (2008) Reregistration Eligibility Decision for Naphthalene, EPA 738-R-07010, Washington, DC, US Environmental Protection Agency.

US EPA (2011) Chemical profiles/consumer products (for naphthalene). Available from: http://scorecard.goodguide.com/ chemical-profiles/consumer-products. tcl?edf_substance_id =91-20-3, Scorecard last accessed on June 13, 2011. 


\section{Batterman et al.}

Van Winkle, M.R. and Scheff, P.A. (2001) Volatile organic compound, polycyclic aromatic hydrocarbons and elements in the air of ten urban homes, Indoor Air, 11, 49-64.

Viau, C., Hakizimana, G. and Bouchard, M. (2000) Indoor exposure to polycyclic aromatic hydrocarbons and carbon monoxide in traditional houses in Burundi, Int Arch Occup Environ Health, 73, 331-338.

WHO. (1997) Chapter 4, Bedbugs, fleas, lice, ticks and mites. In: Rozendaal, J.A. (ed.)
Vector Control. Methods for use by Individuals and Communities, Water, Sanitation Health Program, World Health Organization, Geneva. http:// www.who.int/water_sanitation_health/ resources/vectorcontrol/en/.

WHO. (2010) WHO Guidelines for Indoor Air Quality: Selected Pollutants, Copenhagen, World Health Regional Office for Europe. http://www.euro.who.int/_data/assets/ pdf_file/0009/128169/e94535.pdf.

Wingfors, H., Sjödin, A., Haglund, P. and Brorström-Lundén, E. (2001) Characteri- sation and determination of profiles of polycyclic aromatic hydrocarbons in a traffic tunnel in Gothenburg, Sweden, Atmos. Environ., 35, 6361-6369.

Zielinska, B., Fujita, E., Sagebiel, J., Harshfield, G., Uberna, E., Hayes, T. and Keene, F. (1998) Arizona hazardous air pollutants monitoring program, J. Air Waste Manag. Assoc., 48, 1038-1050. 